\title{
Practice preferences of primary medical care and traditional internal medicine house officers
}

\author{
N. S. PALCHIK†, T. E. DIELMAN†, J. O. WOOLLISCROFT \& J. K. STROSS \\ †Department of Postgraduate Medicine and Health Professions Education and $\ddagger$ Department of Internal \\ Medicine, University of Michigan Medical School, Ann Arbor, Michigan
}

\begin{abstract}
Summary. In an academic medical centre between 1980 and 1985 , the attitudes, preferences and career goals of house officers in a primary medical care residency training programme were assessed at entry and at the end of each house officer year. Primary care trainees who went on to practise in a general medicine setting were compared to primary care trainees who subsequently received subspecialty training and also to traditional internal medicine trainees. House officers in the primary care programme generally maintained attitudes and preferences central to the practice of primary care, and scored significantly higher than traditional track house officers on attitudes and preferences compatible with the practice of medicine in a primary care setting. However, primary care house officers who later went into subspecialty training received scores similar to those of traditional track house officers on practice preferences relating to specialty care. There were no significant differences between primary care and traditional track house officers on standard measures of knowledge and clinical skill.
\end{abstract}

Key words: *Primary health care; internal medicine/*educ; *internship; *attitude of health personnel; goals; Michigan; clinical competence

\section{Introduction}

The goal of residency programmes in internal medicine is to provide the educational experi-

Correspondence: Dr Nancy S. Palchik, Department of Postgraduate Medicine and Health Professions Education, University of Michigan Medical School, Gi I 6 Towsley Center, Ann Arbor, Michigan 48109O20I, USA. ences necessary to prepare trainces to deliver high quality in-patient and out-patient medical care (Reitemeier et al. 1975; Council on General Internal Medicine 1977; Wilson et al. 1983). Although residency training has traditionally been oriented towards in-patient experiences, this emphasis has begun to shift. There are several factors responsible for this shift: a shortage of primary care doctors (Petersdorf 1978; Geyman I986); the evidence that general internists spend over half of their time in out-patient encounters (Reitemeier et al. 1975; Mendenhall et al. I979); changes in the financing of medical care (Perkoff 1986; Schroeder et al. 1986); and changes in the utilization of hospital and ambulatory services (Perkoff I976). At many academic medical centres in the United States, one response has been the development of primary care internal medicine training programmes (Gorol et al. 1975; Liang et al. 1976; Perlman et al. 1976; Boufford 1977; Peaslee \& Sarosi 1978; Mendenhall et al. 1979; Goodson et al. I980, 1986; Dale et al. I98 I; Kurtz I982).

Although the basic knowledge and skills needed to provide competent medical care are similar for both primary care and traditional internal medicine house officers, primary care programmes have given more emphasis to education in ambulatory care, continuous care, non-internal medicine specialties and the psychosocial aspects of illness and health; in contrast, traditional internal medicine residency training has tended to focus on in-patient subspecialty treatment of the seriously and (usually) acutely ill (Goroll et al. 1975; Perlman et al. 1976; Eisenberg 1980; Wartman et al. 1980; Petrusa et al. 1983; Grol et al. 1985). Furthermore, it has been shown 
that the educational setting of a training programme can have a major influence on the career goals and medical practice activity preferences of trainees (Marienfield r977; Petersdorf r978; Goldenberg et al. 1979; Crain et al. 198I; Dale et al. I98I; Weil \& Schleiter 198I). If departments of internal medicine in academic medical centres are to train primary care doctors, care must be taken to ensure that house officers who enter these programmes with a desire to practise general internal medicine are not diverted from their goals (Boufford 1977; Petersdorf 1978; Wartman et al. 1980).

A primary care internal medicine track was initiated at the University of Michigan in July 1977. This track differs from the traditional internal medicine track in that house officers have: a $25 \%$ time commitment to ambulatory care; a separate ambulatory clinic emphasizing continuity of care; a team approach including nurse practitioners and mental health professionals; rotations in other specialties including orthopaedics, gynaecology, otorhinolaryngology, dermatology and neurology; and an emphasis on the biopsychosocial model of illness and health care. Also, sufficient time is provided for traditional rotations on the in-patient services, although less time is available for subspecialty rotations. The present study addresses the following questions: (I) What are the medical practice attitudes, preferences and career goals of primary care internal medicine house officers? (2) How do the attitudes, preferences and career goals of primary care internal medicine house officers compare to those of traditional internal medicine house officers? (3) Are there differences in the attitudes, preferences and career goals of those primary care track trainees who go on to practise in a primary care setting and those who subsequently go into a subspecialty? and (4) Are there differences in the overall performance of house officers in the primary care and traditional training tracks?

\section{Methods}

The University of Michigan Department of Internal Medicine currently has approximately I 20 house officers in its 3-year residency training programme. Each year, six first-year house officers who have declared an interest in the prac- tice or teaching of primary care are invited to participate in the primary care internal medicine residency training track. The remaining house officers constitute the traditional internal medicine training programme. Both groups of house officers are selected through a single match as a part of the National Residency Matching Program. Between 1980 and 1985 , a total of 46 house officers participated in at least $\mathrm{I}$ year of the internal medicine primary care training programme. Thirty-seven house officers completed the programme. Of these, 25 went on to practice in a primary care setting and $\mathrm{I} 2$ continued their training in an internal medicine subspecialty.

\section{Instruments}

Three attitude and preference scales were developed and administered to house officers in the primary care training programme from 1980 to 1985. The three instruments-the Medical Practice Activity Scale, the Attitudes Toward Psychiatry in Medicine Scale and the Career Goals Scale-were completed by 27 entry level, 3 I first-, 35 second- and 35 third-year house officers. Scales were administered to entry level house officers at the beginning of their first year and to all house officer at the end of each residency year. Most primary care house officers were tested on several occasions. During the years 1982 and 1984 , the three scales were also administered to a total of 79 traditional track house officers; of these house officers, 16 were entry level, 3 I were completing their first year, 26 were completing their second year and 6 were completing their third year.

The Medical Practice Activity Scale is composed of questions concerning preferences for types of activities which characterize primary care doctors versus specialty or tertiary care doctors. Each of the 56 items on the scale describes a potential medical practice activity which house officers rate from 'very desirable' (7) to 'not at all desirable' (I) for their own medical practice. Independent subsets of the scale items are summed to form seven subscales based on the results of factor analytic studies. Six of these subscales relate to specific aspects of primary care. These six subscales are: (I) comprehensive care; (2) first contact care; (3) continuity of care; (4) willingness to engage in psychosocial exploration; $(5)$ 
willingness to treat common illness; and (6) interest in treating problems which cross specialty boundaries. The first three subscales describe dimensions of care similar to those used by Mendenhall et al. (1979) to classify primary care practice. Subscales 4,5 and 6 address willingness to assess and treat psychosocial aspects of health care problems; they also address willingness to treat the wide variety of common illnesses that do not fall within the usual purview of internal medicine but were considered by programme teachers to be central to the delivery of primary care. A seventh subscale (specialty care) describes activities unique to a specialty practice.

The Attitudes Toward Psychiatry in Medicine Scale consists of 30 attitude statements which house officers rate on a 6-point scale from 'strongly agree' to 'strongly disagree'. The items are combined to form five subscales based on factor analyses. These subscales address: (I) liking of disturbed patients; (2) interest in psychological medicine; (3) perceived source of problems (moralistic interpretations of psychological problems); (4) patience with patients; and (5) the perceived value of psychological intervention. A validation study of the Attitudes Toward Psychiatry in Medicine Scale (Klos et al. I98I) suggested that the subscales were sensitive to differences in medical specialty, with consultation-liaison psychiatrists exhibiting the most favourable attitudes towards psychiatry in medicine and highly specialized doctors exhibiting the least favourable attitudes.

The Career Goals Scale includes questions concerning preferences on five dimensions of medical practice: (I) percentages of time to be allotted to different types of professional activities: (2) size of community; (3) type of practice setting; (4) type of practice organization; and (s) patient mix.

\section{Data analysis}

A series of one-way analyses of variance was conducted to test the influence of training level on the primary care house officer's attitudes and preferences on the three scales. In addition, those primary care house officers who went on to practise general medicine and those primary care house officers who subsequently went into medical subspecialties were compared to each other and both were compared to traditional track house officers. Two-way analyses of variance were conducted to test the main effects of career path and house officer level. Analyses were performed separately for each subscale. Scheffé post hoc comparisons were used to evaluate the differences between means when the $F$-test in the analysis of variance indicated overall significance. Because of the small number of house officers who were tested on each occasion, and because not all house officers completed the assessment instruments, repeated measures analyses of variance were not conducted. As a result, house officers tested on multiple occasions were treated as independent observations in the analysis of variance by house officer level. This procedure would result in an error in a 'conserservative' direction (i.e. failure to reject the null hypothesis when a 'true' difference exists) as the standard error terms in the repeated measures analyses are reduced by the magnitude of the correlation across occasions on the dependent measures. The performance of primary care and traditional track house officers was assessed on the American Board of Internal Medicine (ABIM) certification examination. Student's $t$-tests were used to compare overall scores, subspecialty scores and patient management problem performance.

\section{Results}

Attitudes, preferences and careers goals of primary care house officers

Medical Practice Activity and Attitudes Toward Psychiatry in Medicine Scales. Mean scores for primary care house officers on the seven Medical Practice Activity subscales were generally high $\left(\geq_{4} \cdot 0\right)$ throughout the study, although interest scores declined significantly after entry into the programme on the subscale related to interests crossing specialties'.

When mean scores on the Attitudes Toward Psychiatry in Medicine Scale were compared for each of the four house officer levels, the highest mean scores were consistently obtained on the subscale labelled 'perceived source of mental disturbance' and the lowest mean scores were obtained on the subscale labelled 'patience with patients'. Mean scores on the subscale 'interest in 
Table 1. Career Goals Scale: mean percentages of time allotted to each medical activity by primary care house officers

\begin{tabular}{|c|c|c|c|c|}
\hline Activity subscale & $\begin{array}{c}\text { Entry } \\
(n=27)\end{array}$ & $\begin{array}{l}\text { First house } \\
\text { officer year } \\
\quad(n=3 \mathrm{I})\end{array}$ & $\begin{array}{l}\text { Second house } \\
\text { officer year } \\
\quad(n=35)\end{array}$ & $\begin{array}{l}\text { Third house } \\
\text { officer year } \\
\quad(n=35)\end{array}$ \\
\hline Primary care & $58 \cdot 3$ & $59 \cdot 5$ & $52 \cdot 5$ & $4^{8 \cdot 7}$ \\
\hline Consultation care & $9 \cdot 7^{2}$ & I $2 \cdot I$ & $17 \cdot 9$ & $20 \cdot 5^{a}$ \\
\hline Subspecialty care & 3.6 & $10 \cdot 0$ & I0. 4 & 10.9 \\
\hline Community/public health & $11 \cdot 9$ & $8 \cdot 4$ & $5 \cdot 3$ & $5 \cdot 5$ \\
\hline Teaching & $9 \cdot 9$ & $8 \cdot \mathrm{I}$ & 8.5 & 8.9 \\
\hline Research & $3 \cdot 3$ & $\mathrm{I} \cdot \mathrm{I}$ & $3 \cdot 5$ & 3.9 \\
\hline Government/administration & $2 \cdot 2$ & $\mathrm{I} \cdot \mathrm{O}$ & I. 3 & $\mathrm{I} \cdot 4$ \\
\hline
\end{tabular}

Note: Superscript letters in common across a row indicate that a pair of means are significantly different at $P<0.05$.

psychological medicine' showed significant declines after entry into the programme, but little difference across house officer years. The remaining subscales indicated no significant differences in attitude by house officer level.

Career Goals Scale. The mean percentages of time that primary care house officers estimated they would like to spend on various medical activities 5 years after the completion of their training are shown in Table I. At each level, house officers indicated that they would like to allocate approximately $50 \%$ of their time to primary care. Preferences for consultation care increased significantly from entry into the programme to completion of the third house officer year. Preferences for community public health involvement resulted in a significant $F$-test, although none of the post hoc comparisons of means was significant.

There were no statistically significant differences in preferred community sizes across primary care house officer levels. Community sizes of 50000-250000 people were the most preferred and community sizes of less than 5000 people were the least preferred. There were also no significant differences in house officer preferences for practice settings. Metropolitan residential and metropolitan suburbs were the most favoured practice locations. Remote and rural areas were the least favoured practice locations.

Primary care house officers at all levels preferred practice in groups of more than four doctors or partnerships of two to four doctors. Military medicine was ranked least desirable, and solo practice was the second least preferred form of organization. With regard to patient mix, pri- mary care house officers preferred to treat bluecollar workers, followed by professionals and other white-collar workers. Unemployed workers and welfare- or Medicaid-supported patients were least preferred.

Comparison of primary care and traditional track house officers

Medical Practice Activities Scale. Primary care house officers who completed the programme and went on to practise general medicine were compared to primary care house officers who went on to receive subspecialty training and to traditional track internal medicine house officers. The results of the two-way analyses of variance conducted to test the main effects of career path and house officer level showed no significant interaction effects and no significant effects by house officer level on any of the subscales of the Medical Practice Activities Scale. However, significant effects by career path were found on all seven subscales. Mean scores by career path are shown in Table 2. Scores of both groups of primary care house officers were significantly higher than scores of traditional track house officers on the six subscales relating to primary care practice. However, on the specialty care subscale, the mean scores of primary care house officers who subsequently went into a subspecialty were not significantly different than the mean scores of traditional track house officers and both were significantly higher than the scores of primary care house officers who went immediately into general practice.

Attitudes Toward Psychiatry in Medicine. The 
Table 2. Mean Medical Practice Activity Scale scores by career path

\begin{tabular}{lccc}
\hline & \multicolumn{2}{c}{ Primary care track } \\
\cline { 2 - 3 } \multicolumn{1}{c}{ Activity scale } & $\begin{array}{c}\text { Graduates directly } \\
\text { entering practice } \\
(n=67)\end{array}$ & $\begin{array}{c}\text { Graduates entering } \\
\text { subspecialty training } \\
(n=35)\end{array}$ & $\begin{array}{c}\text { Traditional track } \\
(n=79)\end{array}$ \\
\hline Comprehensive care & $5 \cdot 5^{\mathrm{a}}$ & $5 \cdot 2^{\mathrm{b}}$ & $4 \cdot 5^{\mathrm{ab}}$ \\
Initial contact care & $5 \cdot 2^{\mathrm{a}}$ & $5 \cdot \mathrm{I}^{\mathrm{b}}$ & $4 \cdot 3^{\mathrm{ab}}$ \\
Continuous care & $5 \cdot 6^{\mathrm{a}}$ & $5 \cdot 3^{\mathrm{b}}$ & $4 \cdot 7^{\mathrm{b}}$ \\
Psychosocial awareness & $4 \cdot 8^{\mathrm{a}}$ & $4 \cdot 6^{\mathrm{b}}$ & $3 \cdot 9^{\mathrm{b}}$ \\
Treatment of common illness & $4 \cdot 7^{\mathrm{a}}$ & $4 \cdot 5^{\mathrm{b}}$ & $3 \cdot 8^{\mathrm{bb}}$ \\
Interests crossing specialties & $4 \cdot 6^{\mathrm{a}}$ & $4 \cdot 4^{\mathrm{b}}$ & $3 \cdot 6^{\mathrm{b}}$ \\
Specialty care & $4 \cdot 4^{\mathrm{ab}}$ & $5 \cdot 0^{\mathrm{b}}$ & $5 \cdot \mathrm{I}^{\mathrm{b}}$ \\
\hline
\end{tabular}

Note: Maximum possible mean score $=7 \cdot 0$. Superscript letters in common across a row indicate that a pair of means are significantly different at $P<0.05$.

two-way analyses of variance of scores on the Attitudes Toward Psychiatry in Medicine subscales showed no significant interaction effects or significant effects by house officer level. The only significant effect by career path was on the subscale labelled 'perceived source of mental disturbance.' Although all three groups of house officers scored relatively high on this subscale, primary care house officers who went into a subspecialty scored significantly lower than traditional track house officers (means of 5.2 and 4.7 respectively).

Career Goals Scale. The analyses of variance of scores on the Career Goals Scale also showed no significant interaction effects or significant effects by house officer level. There were, however, significant effects by career path. The mean percentages of time that house officers in the three career paths wanted to devote to various medical practice activities are shown in Table 3. Primary care house officers who went immediately into practice preferred to devote a significantly greater percentage of their time $(60.8 \%)$ to office- and hospital-based primary care. Traditional track house officers preferred to devote the least amount of time to primary care $(2 \mathrm{I} \cdot 8 \%)$ and the preferences of primary care house officers who went into a subspecialty fell between these two groups $(4 \mathrm{I} \cdot 5 \%)$. The reverse trend was found with preferred time allotments to the practice of subspecialty care, with traditional track house officers allotting significantly more time $(27.0 \%)$ and primary care house officers allotting significantly less time $(3.7 \%)$ to this area. Traditional track house officers allocated significantly more time to teaching and research than either group of primary care house officers and less time to community projects and public health.

There were few differences between primary care and traditional track house officers in their preferences for communities of various sizes. All

Table 3. Career Goals Scale: mean percentage of time allotted to each medical activity by career path

\begin{tabular}{|c|c|c|c|}
\hline \multirow[b]{2}{*}{ Activity scale } & \multicolumn{2}{|c|}{ Primary care track } & \multirow[b]{2}{*}{$\begin{array}{c}\text { Traditional track } \\
\qquad(n=78)\end{array}$} \\
\hline & $\begin{array}{l}\text { Graduates directly } \\
\text { entering practice } \\
\qquad(n=67)\end{array}$ & $\begin{array}{l}\text { Graduates entering } \\
\text { subspecialty training } \\
(n=35)\end{array}$ & \\
\hline Primary care & $60 \cdot 8^{\mathrm{ab}}$ & $4 I \cdot 5^{a c}$ & $2 \mathrm{I} \cdot 8^{\mathrm{bc}}$ \\
\hline Consultative care & $14 \cdot 7^{\mathrm{a}}$ & $23 \cdot 7^{a}$ & I $8 \cdot 3$ \\
\hline Subspecialty care & $3 \cdot 7^{\mathrm{ab}}$ & $17.2^{\mathrm{ac}}$ & $27 \cdot 0^{\mathrm{bc}}$ \\
\hline Community/public health & $6 \cdot 5^{a}$ & $5 \cdot 3$ & $2 \cdot 2^{a}$ \\
\hline Teaching & $9 \cdot 3^{2}$ & $8 \cdot \mathrm{I}^{\mathrm{b}}$ & $\mathrm{I} 4 \cdot 7^{\mathrm{ab}}$ \\
\hline Research & $2 \cdot 5^{2}$ & $3 \cdot 9^{\mathrm{b}}$ & I $5 \cdot 5^{\mathrm{ab}}$ \\
\hline Government/administration & I. 6 & 0.4 & 0.6 \\
\hline
\end{tabular}

Note: Superscript letters in common across a row indicate that a pair of means are significantly different at P<0.05. 
three groups favoured intermediate-sized communities. Very large and very small communities were preferred less, although both groups of primary care house officers ranked smaller communities (5000-10000 people) significantly more favourably than did traditional track house officers. With regard to practice setting preferences, all three groups gave their most favourable rankings to metropolitan residential and surburban settings. Primary care house officers who went into subspecialty training ranked small and rural community settings significantly more favourably and metropolitan cities significantly less favourably than did either the traditional track house officers or primary care house officers who went on to practise in primary care settings.

The preferred types of practice organizations for all three groups of house officers were group practices and partnerships, although primary care house officers entering subspecialty training ranked partnerships significantly higher than did the other two house officer groups. Traditional track house officers gave their most favourable rankings to full-time teaching institutions, ranking these institutions significantly more favourably than did either group of primary care house officers. Both groups of primary care house officers ranked the Health Maintenance Organization (HMO) or prepaid practice plan significantly higher than did traditional track house officers. There were no statistically significant differences by career path in the mix of patients that house officers wanted to treat.

\section{Performance of primary care and traditional track house officers}

Ninety-three per cent of house officers completing the primary care internal medicine track between 1980 and 1984 passed the qualifying examination of the American Board of Internal Medicine. This pass rate is similar to that seen in the traditional internal medicine track $(92 \%)$. Performance on the patient management problems also showed no significant differences.

\section{Discussion}

Recent manpower studies project an increased need for primary care doctors in the United
States (Report of the Graduate Medical Education National Advisory Committee 1980). In European medical education, the need for primary care training has also been identified (Noack I979; Walton I983, I985) and considerable progress has been made in increasing the emphasis on primary care in some educational settings (Metcalfe et al. 1983; Elebute et al. 1986; Howie et al. 1986). However, further academic and professional direction is required if primary care training is to receive sufficient attention in the medical educational systems of many countries (Walton I985).

The present study was designed to assess the attitudes, preferences and career goals of house officers who had declared an interest in primary care internal medicine in a large, academically oriented training programme. The results suggested that even in a traditional academic setting, house officers who entered the primary care programme were able to maintain attitudes and activity preferences central to the practice of medicine in a primary care setting. This may be due to the strength of their preferences prior to entering the residency programme or reflect the impact of the training programme. It also may reflect the nature of trainer-trainee interactions within the programme. In a study of general practice trainees in Manchester, the characteristics of the primary health care trainers were shown to have a significant influence on the progress of trainees in the programme, underscoring the importance of the trainer-trainee relationship (Royal College of General Practitioners I983). In the present study, declines were found in some dimensions of primary care practice over the 3 years of house officer training. However, most of these changes were from entry into the programme to the end of the first house officer year. This is not surprising as this year is critical in developing independence and learning to care for critically ill patients in in-patient settings.

Although the present study was limited to a relatively small number of primary care house officers, significant differences were found by career path on the attitude and preference scales. Even primary care housc officers who subsequently went into subspecialty training scored significantly higher than traditional track house officers on attitudes and preferences compatible with the practice of general medicine. This is 
important as subspecialists spend a substantial portion of their time delivering primary care (Aiken et al. I979; Mendenhall et al. 1979). However, the finding that 12 out of 37 house officers $(32 \%)$ completing the primary care training programme went on to receive further training in an internal medicine subspecialty highlights Peterdorf's (1978) concern that trainees entering internal medicine with an interest in general practice should not be diverted from their goal early in training and drawn into a subspecialty. While this percentage may seem high, it is substantially lower than the $70 \%$ of traditional track trainees who enter subspecialties.

Interpretations of scores of house officers on the Medical Practice Activities Scale and the Career Goals Scale are limited by the absence of formal validity studies of these two measures. Although attempts were made to insure the content validity of the scales by the procedures used to define and sample the content domains, content validation is not sufficient for assessing validity (Carmines \& Zeller 1979). Because of the relatively short follow-up period in the present study, the ability of the scales to predict performance in actual practice could not be determined. However, the scales were able to detect significant differences among the three groups of house officers. In addition, differences in scores on both measures were in the direction expected theoretically. To this extent, the present study provides some evidence for construct validity of these two scales (Cronbach \& Meel I955).

The results of the present study suggest that the medical knowledge and clinical skills of primary care house officers appear to be equal to those of traditional track house officers, supporting the findings of Rosinski \& Dagenais (198I) that primary care house officers are as clinically skilled and grounded in the science of medicine as their counterparts in conventional programmes. The relevance of these results for medical educators lies in the challenge to design residency training programmes which nurture and reinforce interests, attitudes and goals related to primary care practice, while simultaneously providing a setting in which the skills necessary for the delivery of high quality medical care can be acquired with efficiency.

One question which must await the collection of additional data is whether programme evolu- tion and trainee selection procedures have altered the pattern of changes evidenced over the years of residency training. The basic question here is whether house officers' attitudes and preferences which are compatible with the practice of primary care are more favourable and less resistent to change with successive years of programme operation. The relatively small sample of house officers in the primary care track necessitated the use of cross-sectional rather than longitudinal analyses. This problem is common to evaluation studies in primary care because of the small size of the training programmes. Additional research with larger samples of both primary care and traditional house officers is needed to determine patterns of change over the residency training years that might differ between these groups. Further research is also needed to determine the relative influences of the educational programme and trainee selection procedures on the differences observed between primary care and traditional track house officers. As it was not possible to assign house officers randomly to the two training tracks, the differences between primary care and traditional internal medicine house officers may have been due either to differences in the two groups of trainees that led them to selfselect a particular training track, or to differences in the educational emphasis of the two training programmes. Potential differences between the two groups of house officers resulting from participation in the training programme may also have been masked by trainee self-selection procedures. There is, at this stage, no way of separating these effects.

An additional question which needs to be addressed is the generalizability of these results to primary care residency training programmes in non-academic medical centres. Primary care residency training programmes affiliated with academic-based, tertiary care hospitals may show different results from those in other settings. The size of the community in which the training hospital is based may also influence or reflect house officers' attitudes and preferences. The community in which this particular residency training programme is based corresponds to the community size and type preferences of the house officers in the programme, and the practice setting for the primary care residency training programme is a form of group practice. It may be 
that the trainees selected this programme, in part, because it conformed to desired characteristics, or they may have ranked more favourably settings with which they were familiar.

In summary, a primary care training programme in a university-based department of internal medicine has been successful in fostering attitudes, preferences and career goals consistent with the provision of primary care. The performance of primary care trainees on standard examinations has been comparable to trainees in the traditional track, and a high percentage of trainees in the programme have gone on to practice in primary care settings. Although the results of this study are encouraging, it nevertheless raises questions that call for additional investigation. Research in primary care training has only recently begun to reflect the shift in educational emphasis. Additional studies are clearly necessary if we are to produce the types of doctors needed for the care systems now being developed.

\section{Acknowledgements}

The authors would like to thank Amy $T$. Butchart, Stepanie J. Supers and Robert F. Dedrick for assistance with the data analysis, Deborah Ottaway for assistance with the preparation of the manuscript, and the anonymous reviewers for their helpful comments. This work was supported in part by a grant from the US Bureau of Health Professions, Health Resources and Service Administration (No. PEI 5244 ).

\section{References}

Aiken L.H., Lewis C.E., Craig J., Mendenhall R.C., Blendon R.J. \& Rogers D.E. (1979) The contribution of specialists to the delivery of primary care. New England Joumal of Medicine 300, 1 363-70.

Boufford J.I. (1977) Primary care residency training: the first five years. Annals of Internal Medicine 87, $359-68$.

Carmines E.G \& Zeller R.A. (1979) Reliability and Validity Assessment. Sage, Beverly Hills.

Council on General Internal Medicine, American Board of Internal Medicine (1977) Attributes of the general internist and recommendations for training. Annals of Internal Medicine 86, 472-3.

Crain L.S., Dienst E.R. \& Malloy M.J. (1981) The effects of primary care versus traditional training on career choice in pediatrics. Western Journal of Medicine I35, 24, $8-\varsigma$ I.
Cronbach L.J. \& Meel P.E. (1955) Construct validity in psychological tests. Psychological Bulletin 52, 28I302.

Dale D.C., Wallace J.F., Clark H., Rockey P.H., Featherstone H. \& Petersdorf R.G. (r98I) Restructuring an internal medicine residency program to meet regional and national needs for general internists. American Journal of Medicine 70, $1085-90$.

Eisenberg J.M. (1980) Curricula and organization of primary care residencies in internal medicine. Journal of Medical Education 55, 345-53.

Elebute O., Pearson C.A. \& Kale O.A. (1986) Choice of general practice for postgraduate training among medical graduates and undergraduates in Nigeria. Medical Education 20, 349-53.

Geyman J.P. (I986) Training primary care physicians for the 2 ist century. Joumal of the American Medical Association 255, 2631-5.

Goldenberg D.L., Pozen J.T. \& Cohen A.S. (1979) The effects of a primary-care pathway on internal medicine residents' career plans. Annals of Internal Medicine 9I, 271-4.

Goodson J.D., Goroll A.H., Barsky A.J., Treadway K.T., Thibault G.E. \& Stoeckle J.D. (I986) The training of physicians outside the hospital. Archives of Internal Medicine 146, I 805-9.

Goodson J.D., Stockle J.D. \& Leaf A. (1980) Primary care training in a traditional medical residency: an ambulatory care rotation. Journal of Medical Education 55, 950-2.

Goroll A.H., Stockkle J.D., Goldfinger S.E., O'Malley T., May L., Woo B., Follayttar S. \& Sweet R. (1975) Residency training in primary care internal medicine: report of an operational program. Annals of Internal Medicine 83, 872-7.

Graduate Medical Educational National Advisory Committee (I980) Report. Health Resources Administration, Department of Health and Human Services, Hyattsville, Maryland.

Grol R., Tielens V. \& Mokkink H. (1985) Attıtude changes in the vocational training of general practitioners. Medical Education 19, 479-86.

Howic J.G.R., Hannay D.R. \& Stevenson J.S.K. (1986) The Mackenzie Report: General practice in the medical schools of the United Kingdom-1986. British Medical Journal 292, i 567-7 I.

Klos D.M., Dielman T.E., Curtis G. \& Krol R. (I98I) Validation of a scale for measuring attitudes toward psychiatry in medicine. International Joumal of Psychiatric Medicine I1, 161-72.

Kurtz K.J. (1982) Training the internist for primary care: a view from Nevada. Western Joumal of Medicine I36, 76-82.

Liang M.H., Cello J.P. \& Modlin R.K. (I976) Teaching of primary care in an internal medicine residency program. Archives of Internal Medicine 136, 893-6.

Marienfeld R.D. (1977) Comparison of initial house staff goals with eventual career plans in internal medicine. Journal of Medical Education 52, 853-5.

Mendenhall R.C., Tarlov A.R., Girard R.A., Michel J.K. \& Radecki S.E. (1979) A national study of 
internal medicine. Annals of Internal Medicine 9r, $275-87$.

Metcalfe G.C., Freeman G.K., Bain D.J.G. \& Rowe L.J. (1983) Teaching primary medical care in Southampton: the first decade. Lancet i, 679-99.

Noack H. (1978) Medical education and primary health care: Report of the 1976 Berne Conference. Medical Education 12, 7-9.

Peaslee E. \& Sarosi G.A. (1978) Primary care experience in an internal medicine residency. Journal of Medical Education 53, $139-4 \mathrm{I}$.

Perkoff G.T. (1986) Teaching clinical medicine in the ambulatory setting: an idea whose time may have finally come. New England Journal of Medicine 314, 27-3 I.

Perlman L.V., Graham T. \& Christy W. (1976) Primary care internal medicine residencies: definitions, problems, and opportunities. Archives of Internal Medicine I36, i I I-3.

Petersdorf R.G. (1978) The doctor's dilemma. New England Journal of Medicine 299, 628-34.

Petrusa E.R., Yunkwe R. \& Brink S. (1983) Evaluation continuity of care in primary care internal medicine programs. Southern Medical Journal 76, 786-9.

Reitemeier R.J., Spittell J. A., Weeks R.E., Daugherty G.W., Nobrega F.T. \& Fleming R.W. (1975) Participation by internists in primary care. Archives of Internal Medicine 135, 255-7.

Rosinski E.F. \& Dagenais F. (I98I) A comparison of primary care residents with conventional internal medicine and pediatric residents. Western Journal of Medicine 135, 245-7.

Royal College of General Practitioners (1983)
Editorial: Occasional Paper 2 I: Influence of trainers on trainees in general practice. Journal of the Royal College of General Practitioners 33, 3-5.

Schroeder S.A., Showstack J.A. \& Gerbert B. (I986) Residency trainig in internal medicine: time for a change? Annals of Internal Medicine I04, 554-61.

Walton H.J. ( 1983 ) The place of primary health care in medical education in the United Kingdom: a survey. Medical Education 17, I4 I-7.

Walton H.J. (1985) Primary health care in European medical education: a survey. Medical Education $\mathbf{1 9}$, I 67-88.

Wartman S.A., Fulton J.P. \& Wessen A.F. (I980) Increasing the yield of primary care-oriented practitioners from residency programs in internal medicine. Rhode Island Medical Journal 63, 483-6.

Weil P.A. \& Schleiter M.K. (198I) National study of internal medicine manpower: VI. Factors predicting preferences of residents for careers in primary care or subspecialty care and clinical practice or academic medicine. Annals of Internal Medicine 94, $69 \mathrm{I}-703$.

Wilson H.K., Brown H., Keuer S.P., Permutt R.P., Sawyer J.W. \& Lynch E.C. (1983) Residents' perceptions of primary care versus traditional internal medicine programs. Joumal of Medical Education 58, 205-6.

Received is October I986; editorial comments to authors 29 November 1986; 6 March 1987; accepted for publication 27 March 1987 